\title{
Student Errors in Fractions and Possible Causes of These Errors
}

\author{
Nuri Can Aksoy ${ }^{1}$, Derya Ozlem Yazlik ${ }^{2}$ \\ ${ }^{1}$ Hasan Kalyoncu University, Turkey \\ ${ }^{2}$ Nevsehir Hacı Bektas Veli University, Turkey \\ Correspondence: Derya Ozlem Yazlik, Nevsehir Hacı Bektas Veli University, Turkey.
}

Received: October 5, 2017

doi:10.11114/jets.v5i11.2679
Accepted: October 30, $2017 \quad$ Online Published: October 30, 2017

URL: https://doi.org/10.11114/jets.v5i11.2679

\begin{abstract}
In this study, it was aimed to determine the errors and misunderstandings of 5th and 6th grade middle school students in fractions and operations with fractions. For this purpose, the case study model, which is a qualitative research design, was used in the research. In the study, maximum diversity sampling, which is a purposeful sampling method, was used. For this reason, this study was conducted in a state and a private secondary school on a voluntary basis with 1055 th graders and 84 6th graders, with a total of 189 secondary school students from different levels of achievement. In order to determine students' errors and misconceptions about fractions, two tests were prepared by researchers, ten open-ended questions for 5th graders and twelve open-ended questions for 6th graders. Before these tests were formed, the related field was scanned and the existing misunderstandings were determined. Content analysis method was used on the analyzing of the data. The answer papers of the students were coded and students' solving were examined in three categories as correct, wrong and blank. In addition to this the solving belongs to wrong category was examined in detail and mistakes of the students were coded and the reason of these mistakes were dwelled on. It is seen from the result of the study that students have misunderstanding and mistakes about fractions. It is seen that students are not using the modellings on the operations with fractions because of that most of the mistake and misunderstandings are about operations with fractions.
\end{abstract}

Keywords: mathematics education, fractions, errors, misunderstandings

\section{Introduction}

Fractions are one of the richest and most complex topics of mathematics teaching programs. Such a topic that the acquirements related to the fractions take place from the first year of primary school to the 6th grade of secondary school (Alacaci, 2010). Also, it is known that fractions have an important place in teaching advanced mathematical subjects such as algebra (Redmond, 2009). However, the creation and comprehension of the concept of fractions is time consuming and teaching fractions is seen as difficult (Smith, 2002). Therefore, fractions are one of the primary mathematics subjects which are difficult for teachers and students. Moreover, studies show that students have learning difficulties related to the concept of fraction at every class level (Chan, Leu \& Chen, 2007; Isik \& Kar, 2012; Moss \& Case, 1999; Ni \& Zhou, 2005; Olkun \& Toluk, 2003; Olkun \& Toluk-Ucar, 2012; Soylu \& Soylu, 2005; Soylu, 2008; Stafylidou \& Vosniadou, 2004; Unlu \& Ertekin, 2012). The structure of fractions and the teaching method of it can be shown as the basic reason for these difficulties (Birgin \& Gurbuz, 2009; Soylu \& Soylu, 2005; Streefland, 1991; Yilmaz \& Yenilmez, 2008). More of an operational learning is carried out, rather than the conceptual learning in teaching fractions. That is, from the beginning students were asked to make calculations by being given the rules (Aksu, 1997). Consequently, students routinely learn how to operate fractions every year and then forget how to operate them (Siap \& Duru, 2004). Arcavi (2003) and Olkun (2004) indicate that many learners can easily solve division with fractions, but they cannot explain why the second fraction is inverted and multiplied while doing this, therefore, students should be taught the meanings behind these operations instead of make them to memorize the rules. Consequently, the concept of fractions must be taught at the conceptual level and the teaching process must be designed in this way. According to Pesen (2007), in teaching the concept of fractions the part-whole relation must be emphasized first. As for the teaching of part-whole relationship, half-quarter concepts should be comprehended by using geometrical forms such as bread, apple, cardboard and then triangles, rectangles and circles, and then the symbolic representation of fraction numbers should be introduced. In the operations related to the fractions, the models and shapes should be utilized as in natural numbers. In this way, the drawn shapes and the used models will make the question more concrete and easier to understand (Kocaoglu, 2010). Not relating 
the fractions to daily life is another reason why it is being forgotten in a short period of time (Albayrak, 2000). For this reason, it is necessary to write the problem sentences of fractional numbers appropriate to daily life and to concretize it. Thus, the concept of fractions that were abstract for the students will be seen as a part, a necessity of daily life, therefore, meaningful and permanent learning will be performed (Kocaoglu, 2010). Moreover, in order to overcome the deficiencies in the teaching of fractions, teachers need to be aware of the errors that students can make, to take precautions to correct these errors and to arrange the teaching environment accordingly (Soylu \& Soylu, 2005). Therefore, it is important to identify the students' errors related to frictions and the causes of these errors. The lack of knowledge, carelessness and misunderstandings are often seen as the basis for the errors students make. It is particularly important to focus on the misconceptions that students have (Yenilmez \& Yasa, 2008). Because, these misunderstandings not only negatively affect students' learning but also adversely affect their further learning (Baki, 2008). As a result of the literature review, some studieshave been found which analysis the student errors in fractions at all levels of education and the misunderstandings that are the source of these mistakes (Alacaci, 2012; Biber, Tuna \& Aktas, 2013; Demiri, 2013; Devika, 2016; Haser \& Ubuz, 2002; Jigyel \& Afamasaga-Fuata, 2007; Karaagac \& Kose, 2015; Kocaoglu \& Yenilmez, 2010; Meert, Grégoire \& Noël, 2010; Okur \& Cakmak-Gurel, 2016; Pesen, 2007; Pesen, 2008; Soylu \& Soylu, 2005; Stafylidou \& Vosniadou, 2004; Taskın \& Yildiz, 2011; Yilmaz \& Yenilmez, 2007).

When the results obtained from these studies were examined; the study conducted by Soylu and Soylu (2005) shows that 5 th graders have misconceptions about the ordering, addition, subtraction and multiplication in fractions. At the end of the study, it was determined that especially when the students were collecting and multiplying with fractions, they operate the fractions by considering the numerator and denominator as separately and applied the previously learned rules to the subsequent rules. In their study, Haser and Ubuz (2002) found that 5th grade students ignored the rule of separating into equal parts in the case of fraction definitions and indication, and for multiplication, addition and subtraction operations in fractions they maintained the operational habits that they had acquired in natural numbers. Likewise, in Stafylidou and Vosniadou's (2004) study, 37.5\% of the fifth-graders considered fractions as two independent natural numbers. This misconception led children to assume that the value of a fraction increases as the value of either the numerator or denominator increases or that the value of a fraction increases as the value of either the numerator or denominator decreases. Biber, Tuna and Aktas (2013) concluded that the majority of 5th grade students had misconceptions in ordering, addition, subtraction and multiplication of fractions. In this study, the researchers identified three different misconceptions about the addition with fractions. These are; the summation of the numerator and denominator among themselves separately, application of expansion only to the numerator not to denominator, and the summation of the coefficient of expansion with the numerator and denominator. Also, in this study, two different misconceptions related to the multiplication process in fractions were found. The first one is the student's' application of addition rules while doing multiplication with fractions, in other words, multiplying only the numerator and writing denominator as they are without multiplying. The second one is students' multiplication of the numerator of the first fraction with the denominator of the second fraction, and the denominator of the first fraction with the numerator of the second fraction. In his study of the learning difficulties of 3rd grade primary school students and the misconceptions behind their common mistakes, Pesen (2008) identified that some of the students had difficulty in dividing a whole on the numerical axis into mating parts. Again, in this study, it has been seen that some of the students have difficulty in perceiving a $/ b$, the symbolic representation of fraction, as an odd number on the number line, and perceive the numerator and denominator in this number as different numbers. On the other hand, at the end of their study with 7th graders, Karaagac and Kose (2015), determined that students did not totally comprehend the idea that the amount which is represented with fractions will change according to the based whole, therefore, the part-whole relationship in fractions did not fully developed. Likewise, in their study with 5th graders, Kocaoglu and Yenilmez deduced that students did not have a part-whole relationship and they had difficulty in understanding the problems.

As it is mentioned above, it is seen that there are many studies that examined the student misunderstandings on fractions in Literature and in these studies many of the student misunderstandings were identified. In this study, the aim was to completely examine middle school students' misunderstandings about fractions that exist in the Literature or will be detected for the first time. Accordingly, it was aimed to determine the 5th and 6th grade secondary school students' errors and the underlying causes of misunderstandings in relation to fractions and operations with fractions.

\section{Method}

In this study, it was aimed to determine the errors and misunderstandings of 5th and 6th grade middle school students in fractions and operations with fractions. For this purpose, the case study model, which is a qualitative research design, was used in the research. The case study is defined as the in-depth exploration of a specific system (e.g. an activity, event, process, or individuals) with the help of different data collection tools (McMillan \& Schumacher, 2010). Thus, to be able to deeply examine the misconceptions of secondary school students in fractions, the case study model was chosen for this research. 


\subsection{Participant}

In the study, maximum diversity sampling, which is a purposeful sampling method, was used. The main goal in the maximum diversity sampling is to reveal common opinions from different groups (Yildirim \& Simsek, 2006). For this reason, this study was conducted in a state and a private secondary school on a voluntary basis with 1055 th graders and 84 6th graders, with a total of 189 secondary school students from different levels of achievement. The academic standings of the students are determined by the grade average of the mathematics course and the information obtained from the mathematics teachers.

\subsection{Data Collection}

In order to determine students' errors and misconceptions about fractions, two tests were prepared by researchers, ten open-ended questions for 5 th graders and twelve open-ended questions for 6th graders. Before these tests were formed, the related field was scanned and the existing misunderstandings were determined. Then, the 5th and 6 th grade Mathematics textbooks, which are approved by the Ministry of Education Secondary School Mathematics Teaching Program and the Ministry of National Education and Training Board, were examined. In order to ensure the validity of the tests, the opinions of the two field specialists and ten Mathematics teachers, who are working in the applied schools, were taken and in order to control the language, opinions of a Turkish teacher working in secondary school, were taken. The necessary adjustments were made in accordance with the received views.

\subsection{Data Analysis}

In the analysis of the research data, content analysis method was used. The response papers of the students were coded as S1, S2, S3..., S105 for 5th graders; S200, S201..., S284 for 6th graders and the solutions of the students in each question were examined in three categories as correct, incorrect and blank. However, for each question, the solutions in the incorrect category were analyzed in detail and the errors that students made are coded according to their types and the reasons for each type of error are emphasized. According to the explanations made by the students, it was investigated whether these mistakes are caused by misunderstandings or not.

To ensure the reliability of the study, in the analysis of data two expert researchers from Mathematics independently coded the data. By comparing the analysis of these two field experts, the number of overlapping and non-overlapping codes has been determined. By using the formula, (Reliability = number of overlaps / (number of overlaps + number of non-overlaps)) $98 \%$ reliability level was found. In addition, while interpreting the obtained data, direct citations from students' answers were included to ensure reliability and validity.

\section{Findings}

\subsection{Student Errors Related to Ordering in Fractions}

The analysis of the student responses obtained from the questions that were prepared according to the learning outcomes that is based on the 5th grade secondary school curriculum "Unit orders fractions and it orders the fractions that have equal denominators or the fractions that one's denominator is another's multitude" is presented in Table 1.

Table 1. Frequency and percentage values related to the analysis of student responses about ordering in fractions

\begin{tabular}{lllllll}
\hline Class/Question & \multicolumn{2}{l}{ Unanswered } & \multicolumn{2}{l}{ Incorrect } & \multicolumn{2}{c}{ Correct } \\
\hline & f & \% & f & $\%$ & f & $\%$ \\
$5 / 1$ & 25 & 24 & 11 & 10 & 69 & 66 \\
$5 / 6$ & 21 & 20 & 9 & 9 & 75 & 71
\end{tabular}

When Table 1 was examined, it is seen that $66 \%$ of the students answered correctly, $10 \%$ answered incorrectly, and all of the students, who answered incorrectly, made similar mistakes. It is observed here that students think that a fraction with large denominator is also large in the fraction ordering. For this reason, it can be said that $11 \%$ of the students have the misconception that while ordering the fractions with equal numerators. The value of the fraction will increase as the value of the denominator rises. However, it was seen that all the students who made the ordering incorrectly $(10 \%)$ or left the question blank (24\%) were all modeling the problem and doing the modeling correctly, in general. It was also observed that while doing the modeling, some students didn't try to divide the parts equally, although they divide the whole into the right number of parts. As for the reason of these two cases; the lack of drawing ability of the students or not knowing that the fractions will be divided into equal pieces due to its definition can be given. The following is the answer of the S76 coded student.

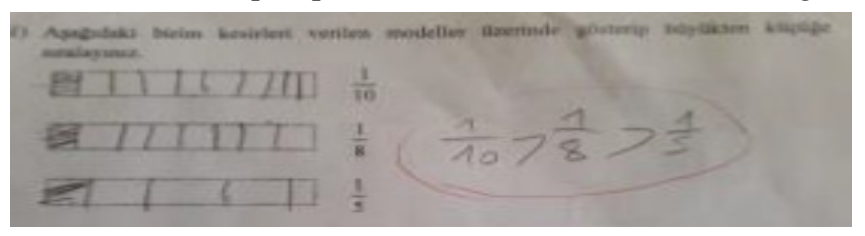


In the 6th question, $71 \%$ of the students answered correctly and $9 \%$ of the students answered incorrectly. In solving this problem, because of the necessity to perform expansion to equalize the denominators, this problem is difficult, but it is noteworthy that the number of students who correctly answered this question is higher than the first question. The reason of this might be giving the readymade models for this question. In this question, three types of student errors were identified. The most common student error, with $67 \%$ because of not knowing the part-whole relationship, is considering the fraction with large numerator and denominator as having large value without equalizing the denominators, as in the 1st question. The second type of error is that $22 \%$ of the students wrote the value of the denominator in the place of numerator and the value of the numerator in the place of denominator. Another type of error, unlike the others, is when the student put the equals sign between fractions; s/he noted with her/his hand writing that from large to small. In this type of errors, from her/his answer to the first question, it can be said that the student doesn't know the equals sign. It can be said that the students do not benefit from the model while ordering the fractions, they do not know that the values in the denominator need to be equalized, or they do not realize that the whole is divided into equal pieces as much as the value of the denominator. The answer of S92 coded student is given below.

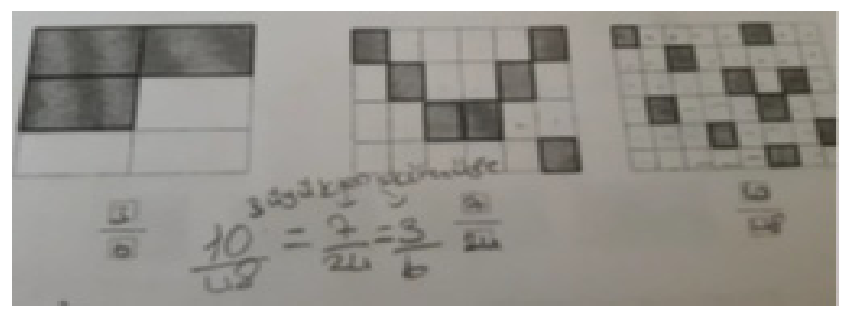

\subsection{Student Errors Related to the Relationship between Compound Fractions and Complex Fractions}

The second question, which has two options, was prepared related to the following learning outcomes that takes place in 5 th grade secondary school curriculum, "Comprehends that the complex fraction the sum total of proper fraction and compound fraction and converses mixed fraction into compound fraction and compound fraction into mixed fraction.", includes 2 varied questions as $2 \mathrm{a}$ and $2 \mathrm{~b}$. Whereas, in $2 \mathrm{a}$, the students were asked to express an integer that corresponds to the model, in $2 \mathrm{~b}$ they were asked to convert the complex fraction that corresponds to the model, to compound fraction. The analysis of the student responses obtained from these questions is presented in Table 2.

Table 2. Frequency and percentage values related to the analysis of students' answers on expressing the given model as complex fraction and converting complex fraction into compound fraction

\begin{tabular}{lllllll}
\hline Class/Question & \multicolumn{2}{l}{ Unanswered } & \multicolumn{2}{l}{ Incorrect } & \multicolumn{2}{c}{ Correct } \\
\hline & $\mathbf{f}$ & $\%$ & $\mathbf{f}$ & $\%$ & $\mathbf{f}$ & $\%$ \\
$5 / 2 \mathrm{a}$ & 1 & 1 & 9 & 9 & 95 & 90 \\
$5 / 2 \mathrm{~b}$ & 2 & 2 & 16 & 15 & 87 & 83 \\
\hline
\end{tabular}

As it is seen from Table 2 that $90 \%$ of the student answers to 2 a were correct but $9 \%$ were incorrect. Student errors that occur when expressing a complex fraction that corresponds to the model are; writing the integer part of the complex fraction incorrectly, writing the unscanned part to the denominator, writing the numerator and denominator in place of each other, and writing the total number of parts to the denominator by dividing the integrals that constitutes the whole parts. It is understood from this that students do not know that the number they need to write to the denominator is the number of the equal pieces of the whole, as in the previous question. It is also apparent that students have difficulty in comprehending the relationship between integer part and the whole in complex fractions. The answers of S53 and S64 coded students are given below.

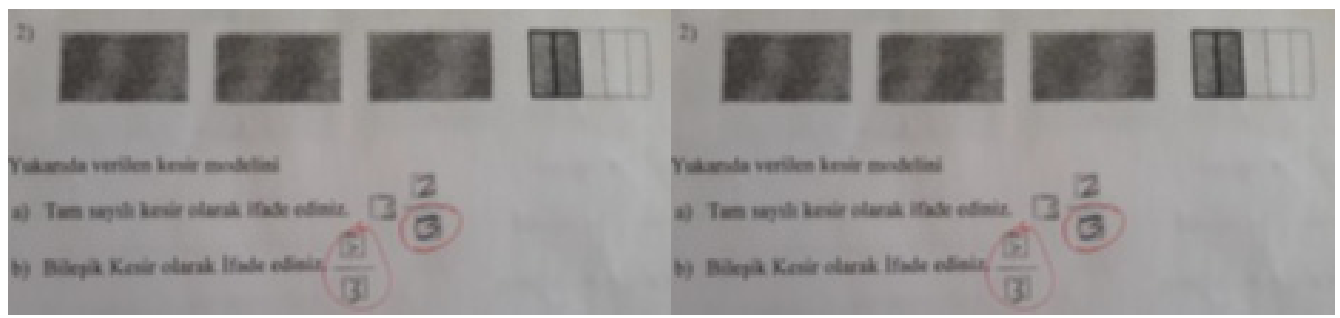

As it is seen, $83 \%$ of the student answers for question $2 \mathrm{~b}$ were correct, $15 \%$ of the answers were incorrect. Hence, it can be said that, students are more successful at expressing the fraction which corresponds to the model than converting complex fraction into compound fraction. It is being estimated that the reason of this difference in success being in favor of question 2a is due to the use of the model. It is also important to note that all students who answered question $2 \mathrm{~b}$ correctly also answered question $2 \mathrm{a}$ in a correct way. 
It is observed that, the number of students making mistake and the kinds of mistakes being made are increasing in the conversion of a complex fraction to a compound fraction. The first one of the mistakes seen in this question is the students' miswriting of the complex fraction based on the model in question 2a. Otherwise, it is seen that, the complex fraction which these students wrote was converted into compound fraction by them correctly. Other encountered errors are as follow: omitting the integer part of a complex fraction and writing the numerator and denominator of the remaining fraction by changing places among each other, writing the total of the integer value and the value of denominator in complex fractions to the denominator by adding them up, writing the total of numerator and denominator to the denominator by adding them up. The answer of S12 coded student is given below.

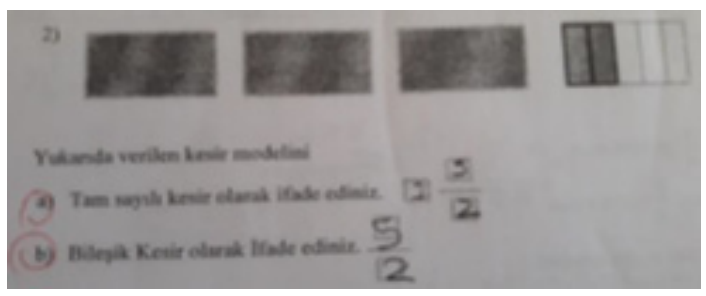

\subsection{Student Errors related to Showing Fractions on Number Line}

An analysis of the student responses obtained from the questions related to the learning outcome that takes place in 5th and 6th grade secondary school curriculum, "Show fractions on the number line", is presented in Table 3.

Table 3. Frequency and percentage values concerning the student responses to questions about showing fractions on the number line

\begin{tabular}{lllllll}
\hline Class/Question & \multicolumn{2}{l}{ Unanswered } & \multicolumn{2}{l}{ Incorrect } & \multicolumn{2}{l}{ Correct } \\
\hline & F & \% & f & $\%$ & f & \% \\
$5 / 3$ & 0 & 0 & 63 & 60 & 42 & 40 \\
$6 / 1$ & 11 & 13 & 58 & 68 & 15 & 19 \\
\hline
\end{tabular}

In the 3 rd question on the test prepared for the 5th graders, students were asked to write to the points which indicate the fractions that correspond to three different points on the number line. When Table 3 is examined, it is seen that $40 \%$ of 5 th graders answered this question correctly and $60 \%$ gave the wrong answer. This success rate shows us that it is quite difficult for students to show fractions on the number line. As for the first reason of the student errors, giving the length between consecutive integer numbers by dividing them into different equal parts on the given number line can be shown. Because, students accepted the number of the parts between the first two integer in the given number line as the number of the parts between two any other integers and write the denominator of these fractions always identically. Additionally, students have fallen into error in determining among which integers the fraction is. It is seen that students wrote " 4 " in the whole part of the fraction when showing the complex fraction which is placed in the number line among the integer numbers, 1 and 2. It is also seen that students very often make mistake when converting fractions into compound fraction. When students were asked to state the fraction that corresponds to a point between the integers, 2 and 3 , on the number line as a compound fraction, it was determined that most of the students wrote the proper fraction part by ignoring the complex fraction part of that fraction. The answers of S6 and S27 coded students are given below.

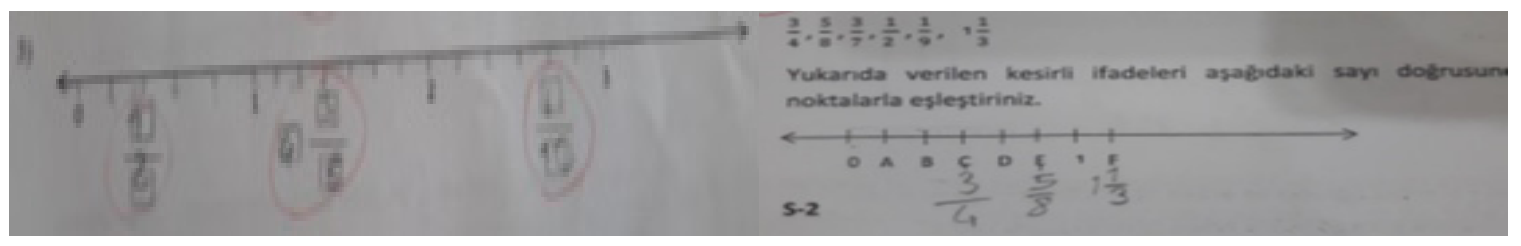

In the 1 st question directed to the 6th grade students, matching the given fractions to the determined points on the given number line was asked. Only $17 \%$ of the students succeeded in this question. This question is one of the most failed questions that both 5th and 6th graders failed at. 6th grade students had difficulty in stating a fraction on the number line, too. In this question, it is also necessary to order fractional expressions from small to large or vice versa, so that, they can match fractional expressions with the points given on the number line. When the answers of the students were examined, the complex fraction which was higher than 1 was being shown correctly on the number line, however, when ordering the fractions which was placed between 0 and 1 , the fraction with the smallest value was again accepted as the largest one by the students, that is to say, it was written on the rightmost side on the number line. In addition, some students wrote $1 / 9$ fraction to the right of 1 on the number line, which means that they made mistake by considering that the fraction, is greater than 1. The answers of S31 and S99 coded students are given below. 


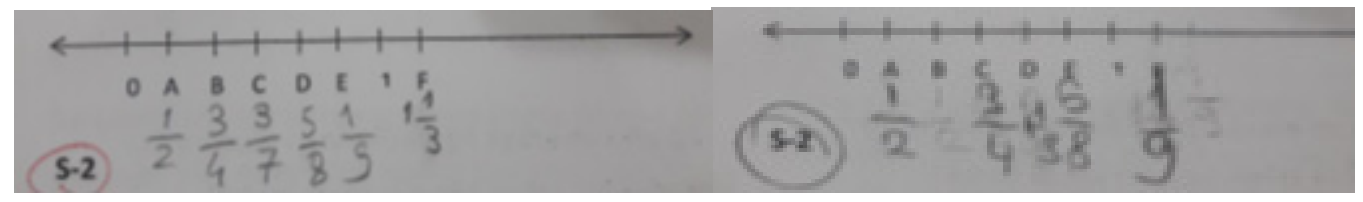

\subsection{Student Errors Related to Addition and Subtraction with Fractional}

The analysis of students responses obtained from the questions related to the learning outcome that takes place in 5th and 6th grade secondary school curriculum which states that "Solves the problems that requires addition and subtraction with the fractions which have equal denominators or the fractions whose numerator is the multitude of the other, and adds-subtracts and interpret two fractions with equal denominator or fractions whose denominator is the multitude of the other, and adds subtract fractions" is presented in Table 4.

Table 4. Frequency and percentage values related to students responses to questions on addition and subtraction with fractions

\begin{tabular}{lllllll}
\hline Class/Question & \multicolumn{2}{l}{ Unanswered } & \multicolumn{2}{l}{ Incorrect } & \multicolumn{2}{c}{ Correct } \\
\hline & $\mathrm{f}$ & $\%$ & $\mathrm{f}$ & $\%$ & $\mathrm{f}$ & $\%$ \\
$5 / 8$ & 8 & 8 & 9 & 9 & 88 & 83 \\
$5 / 9$ & 8 & 8 & 12 & 11 & 85 & 81 \\
$5 / 10 \mathrm{a}$ & 2 & 2 & 13 & 12 & 90 & 86 \\
$5 / 10 \mathrm{~b}$ & 5 & 5 & 33 & 31 & 67 & 64 \\
$5 / 10 \mathrm{c}$ & 2 & 2 & 19 & 18 & 84 & 80 \\
$5 / 10 \mathrm{~d}$ & 2 & 2 & 17 & 16 & 86 & 82 \\
$5 / 10 \mathrm{e}$ & 3 & 3 & 30 & 29 & 72 & 68 \\
$5 / 10 \mathrm{f}$ & 5 & 5 & 49 & 47 & 51 & 48 \\
$5 / 10 \mathrm{~g}$ & 11 & 10 & 32 & 30 & 62 & 60 \\
$5 / 10 \mathrm{~g}$ & 8 & 8 & 38 & 36 & 59 & 56 \\
$6 / 2$ & 9 & 11 & 43 & 51 & 33 & 38 \\
\hline
\end{tabular}

In questions 8 and 9 that were directed to fifth grade students; the problems that require addition and subtraction with fractions were included. When student answers were examined, it is seen that the success rate of these questions is over $80 \%$. It was seen here that some of the students understood that they need to carry out a summation however, they state the result of that summation by writing it only to the numerator value, and so, again they had difficulty in comprehending the relationship between numerator and denominator. The answers of the S10 coded student to the 8th and 9th questions are given below.

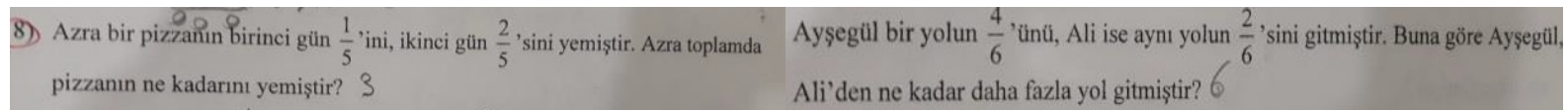

It has been determined that some of the students do not understand that they have to apply addition and they apply subtraction and multiplication instead. It was also found that they also did not perform the transactions correctly during these operations. The answers of S21, S33, S42 and S56 coded students are given below.

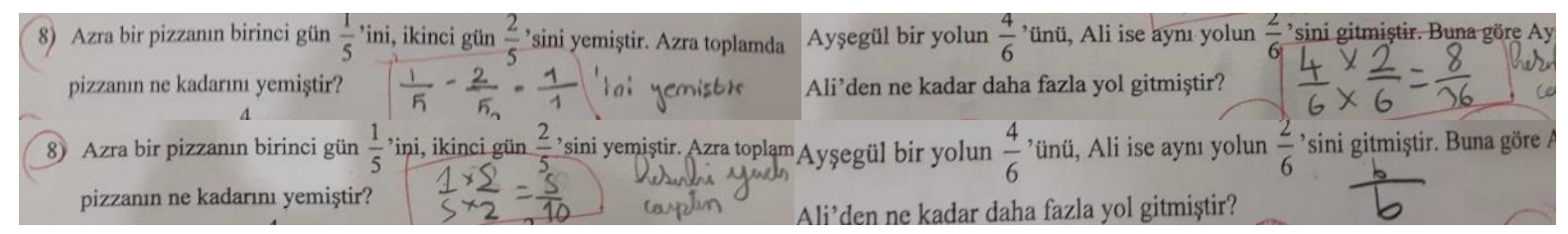

In the 10th question, directed to the 5th grade students of the secondary school, it is aimed to examine the ability of the students to perform addition and subtraction operations with fractions. The success rates of the questions 10a, 10b, 10c and $10 \mathrm{~d}$, which require addition and subtraction with fractions, are around $80 \%$, and it is seen that the students are highly successful. However, in $10 \mathrm{e}, 10 \mathrm{f}, 10 \mathrm{~g}$ and $10 \mathrm{~g}$, which require collection and subtraction with complex fractions, the success rate decreased to $50 \%$.

The success rate of the question $10 \mathrm{a}$, which requires addition with fractions that have common denominator, is $85 \%$. It is seen that the majority of the students, who responded incorrectly, adds up the statements in the numerators and write the total to the numerator and adds up the statements in the denominators and write the total to the denominator as in $10 \mathrm{~b}, 10 \mathrm{c}$. In 10b, students were asked to add two fractions whose denominators are multitude of each other. The success rate has decreased to $63 \%$. This indicates that, students have difficulty in operations of denominator equalization or they are unfamiliar with these operations. In addition, another observed mistake in this question is writing the value of 
denominator of the fraction with the greatest denominator value to the result statement without equalizing the denominators, and directly adding up the denominators and writing it to the numerator. Hence, it can be said that the students perceive numerator and denominator as different numbers and couldn't comprehend the principle of equipartition which was referred in the concept of denominator. The answers of S7, S18 and S21 coded students are given below.

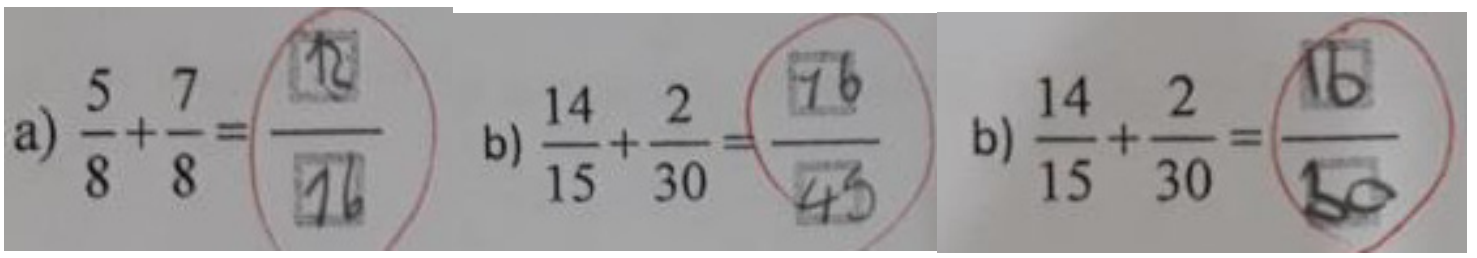

In the following question, 10c, students were asked to perform addition with two complex fractions which have common denominators. In this question, the student success is $80 \%$. However, it has been determined that some of the students came to a new two-digit numerator result by adding up the values of the whole part with each other and by adding up the values in the numerator with each other and writing them alongside. The answers of S20 and S21 coded students are given below.

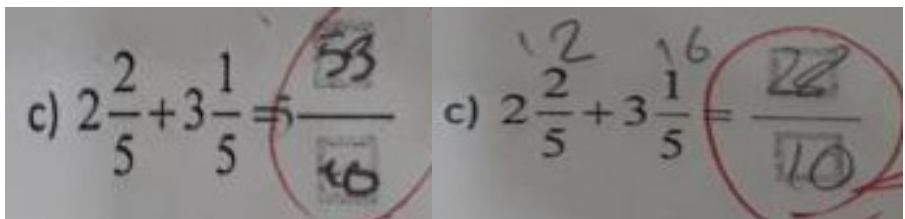

In the question $10 \mathrm{~d}$, directed to the students, the subtraction with proper fractions that have equal numerators takes place. In this question, the success rate of the students is $81 \%$. In this question, as in the previous questions, it is seen that the students perceive the numerator and denominator separately as in $10 \mathrm{e}, 10 \mathrm{~g}, 10 \mathrm{~g}$ therefore, also when applying subtraction; they found the denominator as "0" by subtracting denominators from each other. The answer of S22 coded student is given below.

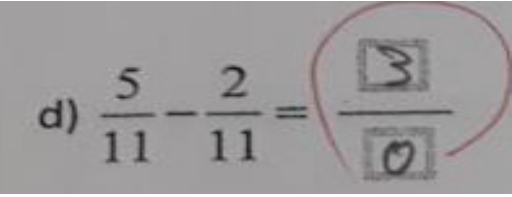

In question 10e, which requires subtraction with two complex fractions that have equal denominators. It has been determined that some of the students stated the whole part of the result fraction correctly by subtracting the values in the whole part from each other, however, they continued to fail at expressing denominator. A student was found to have made a transaction error. The answers of S3, S14 and S25 coded students are given below.

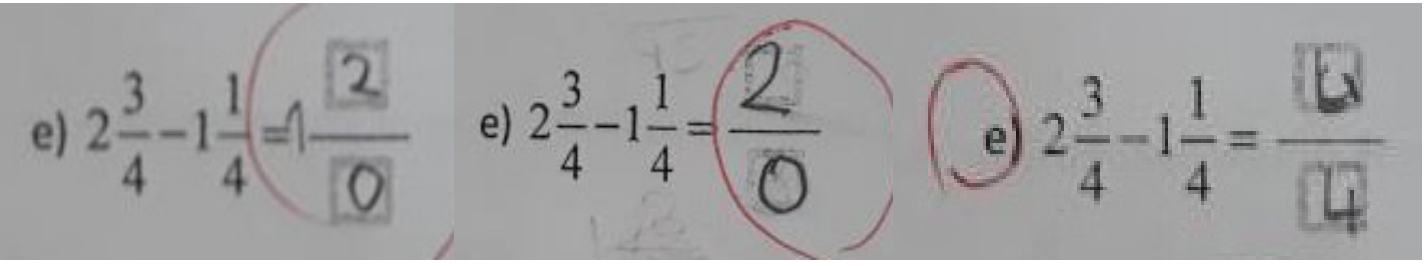

Among 10th questions which include transactional questions, $10 \mathrm{f}$ has the lowest success rate (48\%) and 9 varied errors were encountered in that question. One of the common aspects of these errors is that the students carry on with the previous questions' errors in denominator equalization. The students, again, tried to reach the result by adding up the denominators. As it can be seen from one of the errors of the students on the visual, they correctly operated the conversion of complex fraction to compound fraction on the operation but during the summation, they added up also the denominators and write it to the result of the transaction's denominator. Moreover, another determined error is the error of writing the denominator of the fraction with the large denominator as the result denominator without equalizing the denominators. Beside transaction error, it is noticed that most of the students who answered this question correctly preferred the route to convert complex fraction to compound fraction and get the result by equalizing the denominators instead of writing the result directly by adding up the complex fractions as they are. Based on the student mistakes and the way of the solution of the students who answered correctly, it is seen that while operating addition with complex fractions, they had difficulty in writing it directly to the result by adding up the integers. The answers of S60, S63, S79 and S104 coded students are given below. 


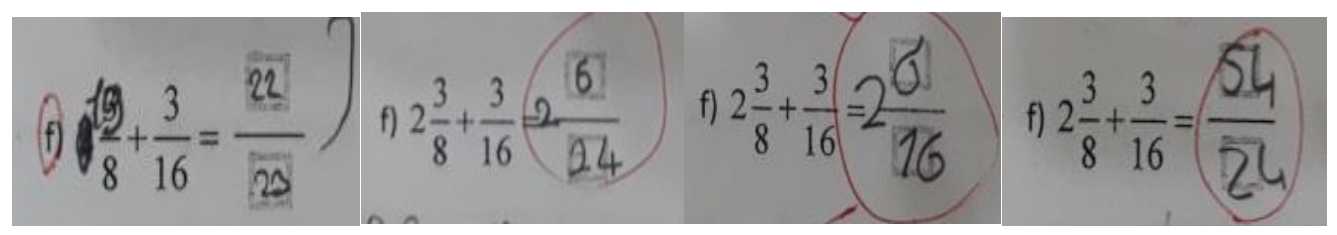

When student errors in $10 \mathrm{~g}$ and $10 \breve{\mathrm{g}}$ questions, which require addition and subtraction of complex fraction and a proper fraction, were examined, it was seen that students could not express integers as a fraction. Here, it is seen that the students write " 0 " to the denominator or the numerator of the integer. It has also been determined that, while converting the integer into a fraction, they write the integer both to the numerator and the denominator. The answers of S38, S43, S44, S51, S82 and S95 coded students are given below.
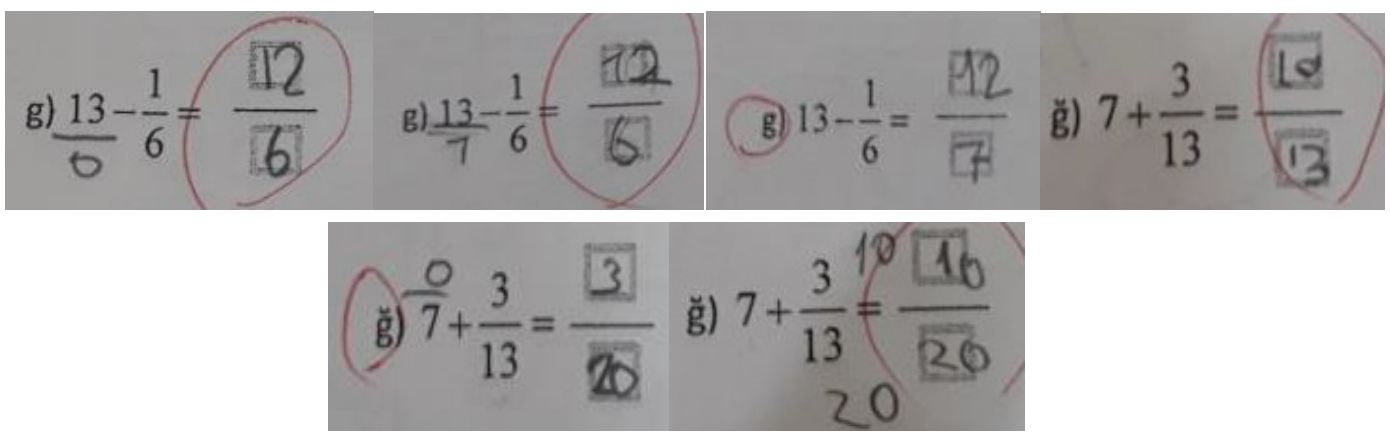

The 2nd question, addressed to the 6th grade students, included a problem that involves complex and proper fractions. To solve this problem, students are expected to perform addition and subtraction. In this question, the success rate of the students is $38 \%$. Two kinds of errors were encountered, when the student answers were examined: the errors that were caused by the student's misunderstanding of the question and the errors that were caused by the lack of pre-existing knowledge during the transaction, although the students had comprehended the necessary transactions to solve the problem. There were also transaction errors. When the students' transactions with the given fractions were examined, it is identified that they perceive numerator and denominator separately as 5th graders did. The answers of S75, S82, S103 and S205 coded students are given below.

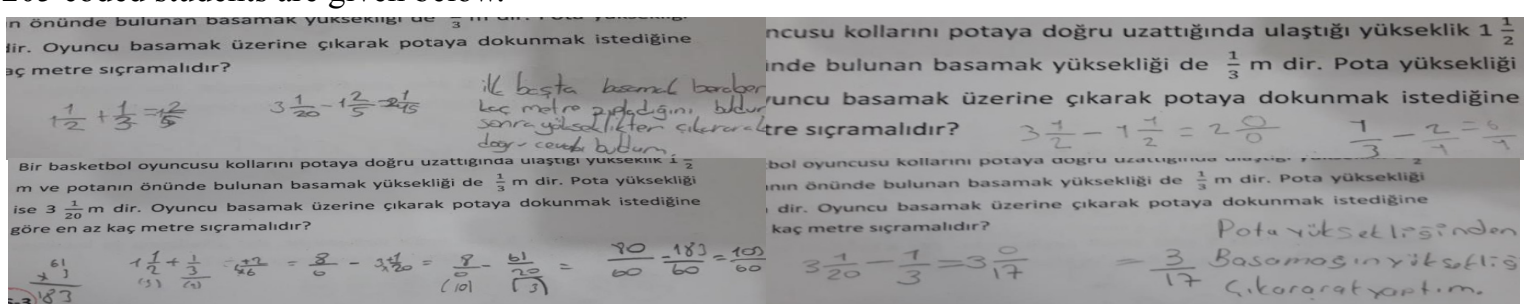

3.5 Student Errors Related to Multiplication-Division Transactions with Fractions (from Part to Whole, from Whole to Part)

The learning outcomes of 5th and 6th grades " calculates a multitude as much as an asked proper fraction and all of a multitude that was given as much as the proper fraction by using unit fractions" and the learning outcome of 6th grade middle school " multiplies and interprets the transaction of a natural number and a fraction, multiplies and interprets two fractions, divides and interprets a natural number to a unit fraction and a unit fraction to a natural number, divides and interprets two fractions, solves the related problems" are given in table 5. 
Table 5. Frequency and percentage values of analysis related to student responses to questions about multiplication and division with fractions

\begin{tabular}{lllllll}
\hline Class/Question & \multicolumn{2}{l}{ Unanswered } & \multicolumn{2}{l}{ Incorrect } & \multicolumn{2}{l}{ Correct } \\
\hline & $\mathrm{f}$ & $\%$ & $\mathrm{f}$ & $\%$ & $\mathrm{f}$ & $\%$ \\
$5 / 4$ & 8 & 8 & 56 & 53 & 88 & 39 \\
$5 / 7 \mathrm{a}$ & 11 & 10 & 27 & 26 & 85 & 64 \\
$5 / 7 \mathrm{~b}$ & 13 & 12 & 24 & 23 & 68 & 65 \\
$5 / 7 \mathrm{c}$ & 14 & 13 & 34 & 32 & 57 & 55 \\
$5 / 7 \mathrm{~d}$ & 15 & 14 & 35 & 33 & 55 & 53 \\
$6 / 3$ & 6 & 7 & 33 & 39 & 46 & 54 \\
$6 / 4$ & 5 & 6 & 32 & 38 & 48 & 56 \\
$6 / 5$ & 5 & 6 & 32 & 38 & 48 & 56 \\
$6 / 6$ & 3 & 4 & 35 & 41 & 47 & 55 \\
$6 / 7$ & 2 & 2 & 63 & 74 & 20 & 24 \\
$6 / 8$ & 11 & 13 & 61 & 72 & 13 & 15 \\
$6 / 9$ & 12 & 14 & 37 & 44 & 36 & 42 \\
\hline
\end{tabular}

In the 4th question, directed to the 5th grade students, a problem that includes a complex and a proper fraction was given. To solve this problem, it is necessary for the students to multiply the integer with the proper fraction. In this question, the success rate of the students is $39 \%$. When the student answers were examined, it was determined that students understood that they had to multiply "15" with the proper fraction "1/4" however, they multiplied "15" with the number "4" that takes place in the denominator of the proper fraction. It is inferred from that the students repeated their previous errors, they failed in expressing integers as fractions and as a result they made error. It also remarks that in this question some of the students solved the problem by adding up " $1 / 4$ " 15 times which was written alongside, instead of multiplying "15" with " $1 / 4$ ". In addition, it has been determined that some of the students have stated their results as 3 liters and $75 \mathrm{ml}$ or 3 liters and 250 gr. The answers of S36, S49 and S77 coded students are given below.

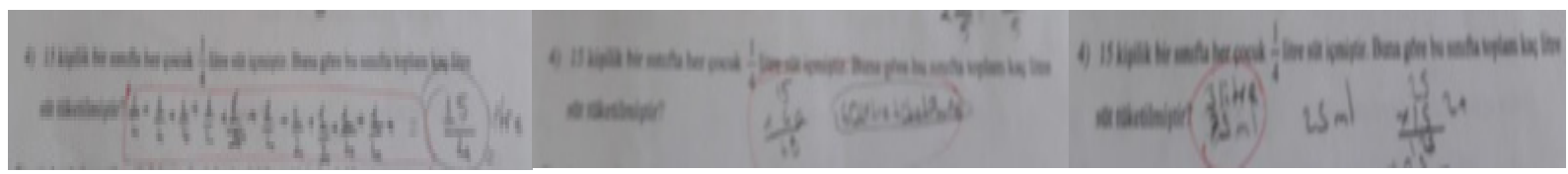

In questions, $7 \mathrm{a}$ and $7 \mathrm{~b}$, students were given whole and asked to find the part. In these questions, the success rates of the students are $63 \%$ and $64 \%$ respectively. When the given answers of these questions were examined, it is seen that students divided the whole with the value of the numerator and multiplied the obtained result with the value of the denominator, while finding the parts of the whole, they added up the whole with the given fraction instead of multiplication and by multiplying the numbers in the numerator and denominator that take place in the fractional expression which points out the asked part, they subtracted the result from the given whole. The answers of S18 and S49 coded students are given below.

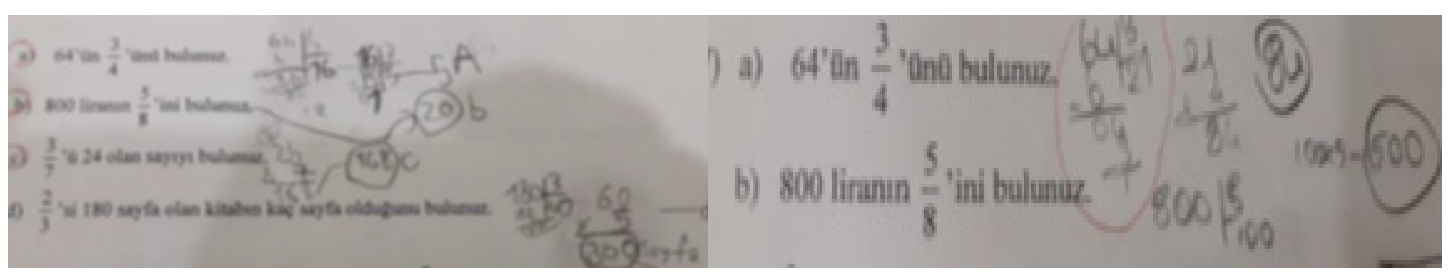

In question $7 \mathrm{c}$ and $7 \mathrm{~d}$, students were given pieces and asked to find the whole. The widespread mistakes are as follows; dividing the given pieces to the value of the denominator of the fractional statement and multiplying it to the value of the numerator, adding the fractional statement to the number that is stated as part by multiplying the numerator and denominator of the fractional statement or multiplying it again with the number that is stated as part, adding up numerator and denominator and multiplying it with the corresponding of the equal part, addition of the given fraction with the piece. The answers of S20, S51 and S74 coded students are given below.

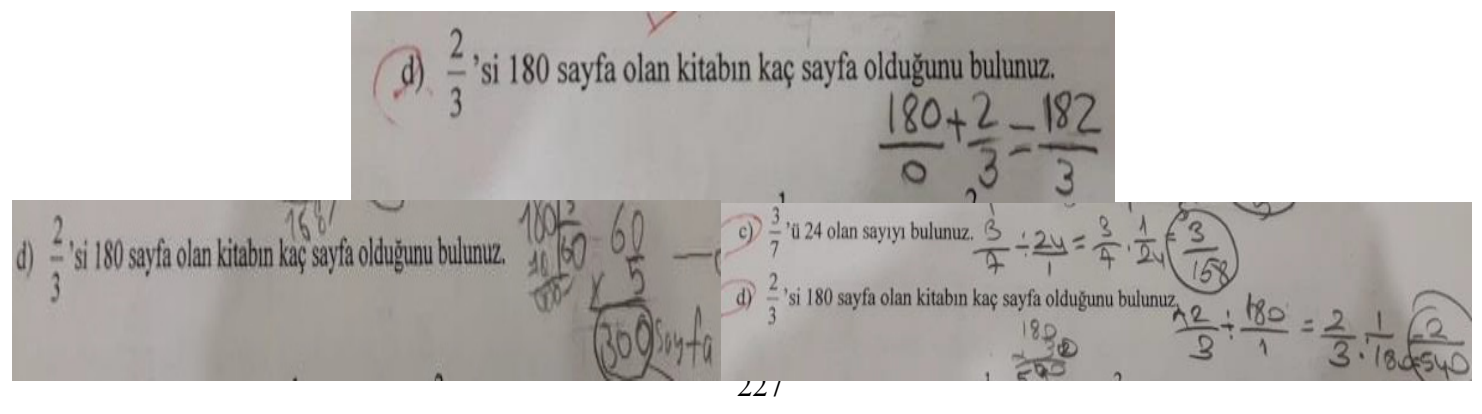


Problems, that require multiplication-division with fractions, were directed to 6 th grade students as questions $3,4,5,6$, 7, 8 and 9. When the success percentages were examined, it is seen that the questions $3,4,5$ and 6 and; questions 7,8 and 9 are divided into two groups. In the first group, the percentage of students' success is moderate, around 55\%, while the percentage of success in the second group is low.

In the 3rd and 4th questions which were directed to the students, they were asked to multiply an integer and a fraction, and only numerical values were changed among these questions. The success rates of the students were almost equal and the mistakes they made were common. It has been determined that some of the students did not understand the given problem therefore; they applied to a different transaction in order to solve the problem. It is seen that some of the students who understand that they need to perform multiplication for the solution of the problem, equalized the denominators before multiplication and then multiplied or instead of multiplication they applied addition and get the result. In addition to these, it was observed that, again, students could not state integer as fraction, wrote " 0 " to the numerator and denominator of the integer therefore, because of the errors they previously acquired, they could not answer correctly. The answers of S216, S237 and S258 coded students are given below.

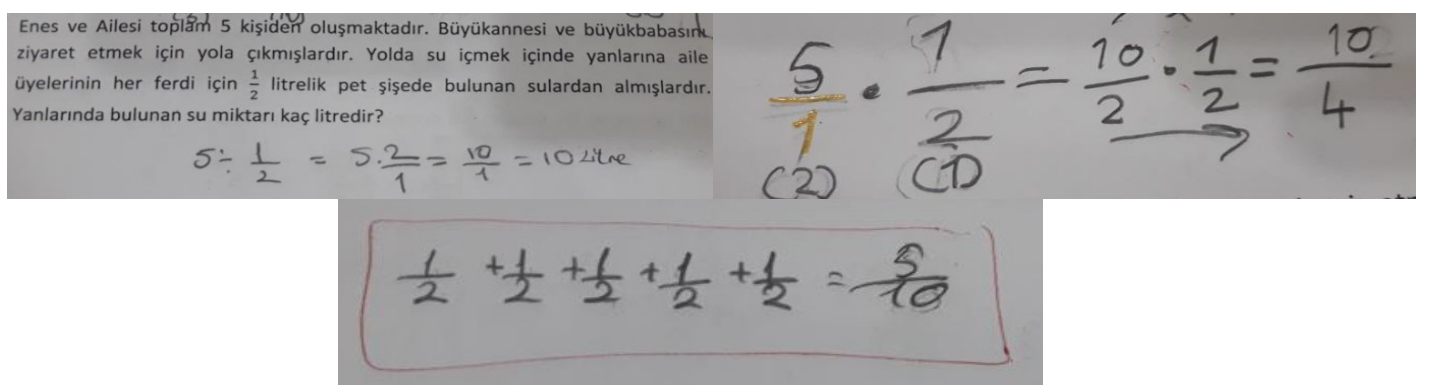

In the 5th question, students were asked to scan to represent the $3 / 8$ of the half of the given model. However, it is seen that the students did not divide the half of the model but divided the all of it or scanned the 3 pieces out of 4 that takes place in the model. Thus, as it is understood that the students have difficulty in understanding what they read or showing what they understood on the model. The answers of S210 and S231 coded students are given below.

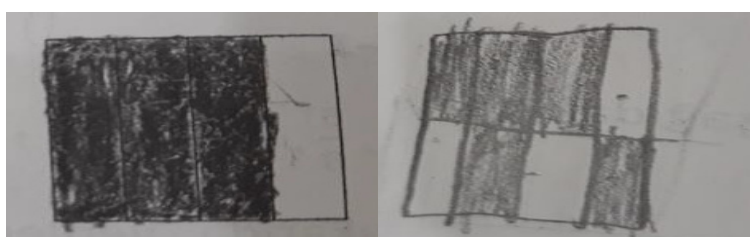

In the 6th question, students were asked to find the part of a whole. When the errors of the students were examined, it is seen that some of the students did not understand the problem therefore, they applied the wrong transactions, as for the ones who understood the problem, and they failed at finding the correct result because of the previous errors they made during the transaction. The answers of S232 and S243 coded students are given below.

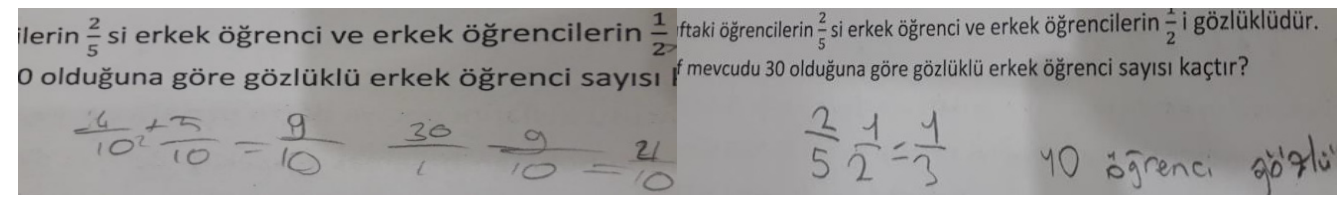

In the 7 th question, students were asked to divide a fraction with an integer. When the students' errors were examined, it was observed that the students found the number of Hazar who was mentioned in the question and her friends but they did not pay attention or they forget to subtract the found result from Hazar herself because of being asked to find the number of Hazar's friends in the question. It is seen that almost all of the students, who made error, fallen into this same error. The other mistakes that were made are due to the students' lack of understanding of the problem. The answer of $\mathrm{S} 244$ coded student is given below.

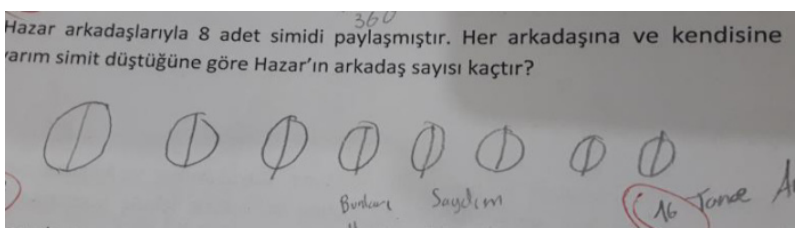


In order to solve the problems in the 8th and 9th questions, that were directed to the 6th grade students, they were expected find the result by using division in fractions. However, it is observed that some of the students did not understand the problem, consequently, they applied multiplication instead of division and some of them applied addition. It was also observed that while students were making these operations, it is seen that they fallen into the same errors again and they made calculation errors. The answers of S255, S264, S267 and S278 coded students are given below.

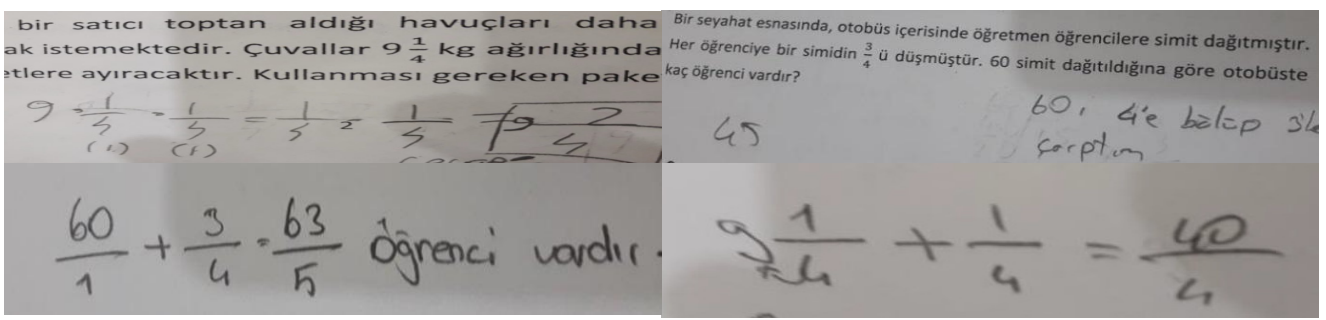

\subsection{Student Mistakes Related to Modeling Equivalent Fractions and Operations That Require Expressing Equivalent Fractions}

The analysis of the student responses obtained from the questions related to the learning outcomes of middle school 5th grade "understands that abbreviation and expansion does not change the value of the fraction and forms fractions that are equivalent to a fraction" is presented in Table 6.

Table 6. Frequency and percentage values related to the analysis of student responses to questions about modeling equivalent fractions and expressing equivalent fractions

\begin{tabular}{lllllll}
\hline Class/Question & Blank & \multicolumn{2}{l}{ Incorrect } & \multicolumn{2}{r}{ Correct } \\
\hline & $\mathrm{f}$ & $\%$ & $\mathrm{f}$ & $\%$ & $\mathrm{f}$ & $\%$ \\
$5 / 5 \mathrm{a}$ & 5 & 5 & 60 & 57 & 40 & 38 \\
$5 / 5 \mathrm{~b}$ & 1 & 1 & 39 & 37 & 65 & 62
\end{tabular}

In the question $5 \mathrm{a}$, the students were given four different fractions, which were equivalent to each other, and students were asked to determine the values of some numerators and some denominators of these fractions. The success rate of this question is $38 \%$. This question has the lowest success rate among the questions directed to 5 th grade students. The students made one, two or three of the fractions that they were to equalize, incorrectly. When the student errors were examined, it was seen that the students did not understand the ratio between the numerator and the denominator in equivalent fractions; they expanded the numerator and denominator with different numbers. It has also been observed that the students made errors while applying multiplication. The answers of S43, S57, S62, S64 and S99 coded students are given below.

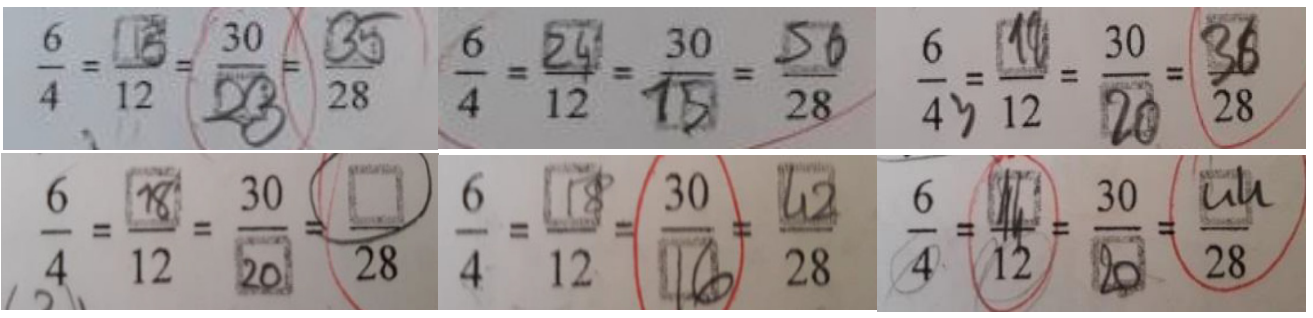

In question $5 \mathrm{~b}$, students were asked to equalize the given fractions by using model. In this question, the percentage of success is $61 \%$. Compared to the previous question, 5a, the usage of model can be shown as the reason of the increase in the percentage of success in question 5b. Moreover, when the answers were examined, it is seen that, although the students showed the equivalent fractions on the model correctly, they had difficulty in expressing it fractionally. It was observed that students correctly identified the denominator by counting the given equal division in the model but they had troubles in finding the numerator and wrote the first number that takes place in the numerator again as the numerator in the equivalent fraction. Because of being done only by one student, it can be interpreted as the inattentiveness of the student. The answers of S13, S26, S34 and S48 coded students are given below.

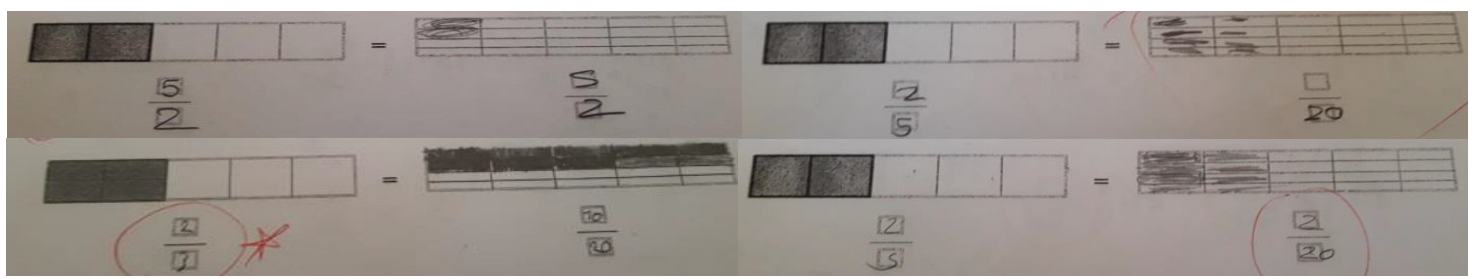




\subsection{Student Errors Related to Operations That Require Problem Solving with Fractions}

Analysis of the student responses obtained from the questions related to the learning achievements of 6th grade secondary school, "estimates the results of the transactions with fractions" and "solves the problems that require transactions with fractions" is presented in Table 7.

Table 7. Frequency and percentage values related to the analysis of student responses to questions related to problem solving with fractions

\begin{tabular}{lllllll}
\hline Class/Question & \multicolumn{2}{l}{ Blank } & \multicolumn{2}{l}{ Incorrect } & \multicolumn{2}{c}{ Correct } \\
\hline & $\mathrm{f}$ & $\%$ & $\mathrm{f}$ & $\%$ & $\mathrm{f}$ & $\%$ \\
$6 / 10$ & 10 & 12 & 38 & 45 & 37 & 43 \\
$6 / 11$ & 14 & 16 & 53 & 62 & 18 & 22 \\
$6 / 12$ & 12 & 14 & 48 & 56 & 25 & 30 \\
\hline
\end{tabular}

The 10th, 11th and 12th questions, addressed to the 6th graders, students were asked to solve the problems that require transaction with fractions, and especially in 11th question they were asked to make predictions about the result after reading the problem.

The success rate of students in 10th question is $43 \%$ which is higher than 11 th and 12th questions. To solve this problem, it has been determined that students generally diagrammatized or proportioned. Examining the answers of the students, who solved this problem incorrectly, showed us that students set up the proportion incorrectly while trying to get the result with the help of proportion, diagrammatized incorrectly while trying to find the solution by setting up a model, they couldn't make sense of the notions of half and quarter and lastly it is seen that some of the students tried to find the result by making random transactions with the given numbers in the question without understanding the problem. The answers of S216, S237, S258 and S284 coded students are given below.

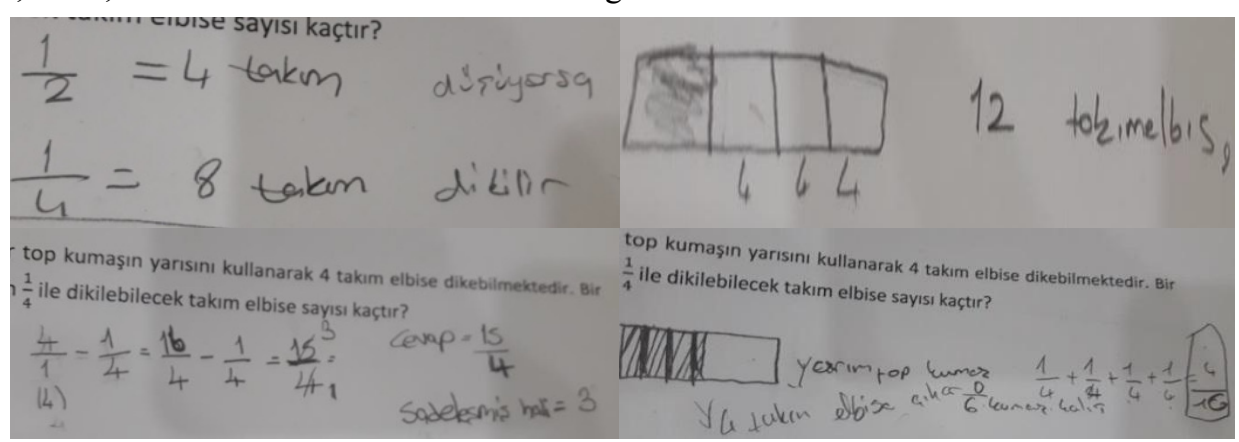

In the 11th question, the students were directed a problem that they could solve by doing subtraction with two complex fractions, whose denominators are multitude of integer of each other, and they were asked to make estimations before solving the problem. The success rate of this problem is $21 \%$. It has also been determined that, some of the students tried to solve the question instead of guessing the result of the problem, and then made estimation according to the result. In addition, it has been determined that one of the students got the approximate result in his/her estimation but in the solution of the problem, s/he made mistake by adding up two complex fractions instead of subtraction. When the errors were examined, it is found that some of the students used addition to find out the height difference between the two trees, that was asked in the problem, instead of subtraction, and as for the some of the students who understood that subtraction is required to solve this problem, it is seen that they did not equalize the denominator during the subtraction, moreover, they subtracted the numbers that takes place in the numerator and denominator from each other. The answers of S240 and S251 coded students are given below.

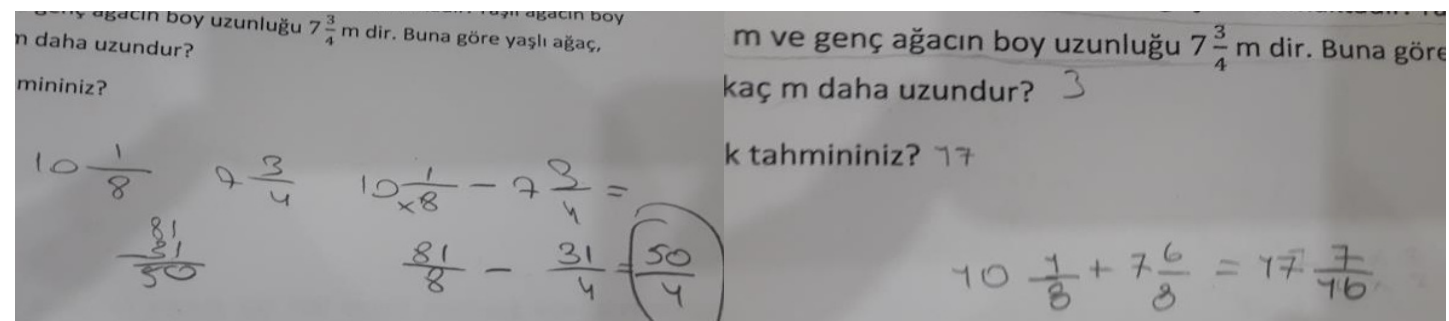

The other two problems in the 12th question are more complex problems that require more transactions than the 10th and 11th questions. Nevertheless, it is seen that the percentage of success in this problem is $42 \%$ and it has a quite well compared to other questions. When the errors were examined, it is seen that almost all of the students did not read the problem carefully and missed the "remaining" statement in the "second week remaining olive oil" which takes place in 
the question, and they got the whole by adding up the fractional expressions that correspond to the sales, thus, they deduced that all of the olive oil had been sold. The answers of S212 and S225 coded students are given below.

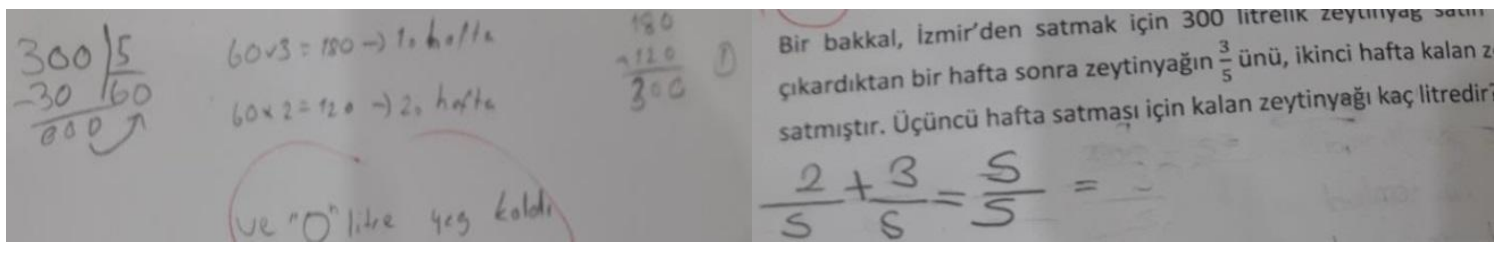

\section{Conclusion and Discussion}

When the findings are examined, it is seen that students made errors in the equalization of the parts that takes place in the concept of fractions, identification of complex fraction on model, expressing complex fraction as fraction, conversion of complex fraction to compound fraction, multiplication and division with fractions, the relationship between part and whole, understanding what they read and the mathematical discourse. It has also been determined that students have difficulty in estimating the result of the problem.

It has been determined that, the students did not pay attention to the equality of the parts that take place in the definition of the fraction when modeling or showing fractional expressions on the number line. It was observed that the students were successful in modeling the given fraction but didn't try to divide parts equally when modeling. As for the reason of these, the lack of drawing ability or not knowing that the whole which takes place in the description of the fractional expressions need to be divided into equal parts, can be shown. It was also determined that the students neglected the number of the equal parts, which take place among the other complex fractions, by accepting the number of the equal divisions between two integers, that are consecutive on three different complex fractions which was given on the number line, up to the number of the divisions between the first two integers. For this reason, it has been seen that they have misstated the denominator of the fraction that corresponds to the given point on the number line. Similarly, while Pesen (2008) found that some of the 3rd grade primary school students had difficulty in separating a whole, that is on the number line, into equal parts, Haser and Ubuz (2002) determined that 5th grade students ignored the rule of division of equal parts in the situations of fractional definition and expressions. When the results of these studies were examined, it can be said that students couldn't comprehend the equalization of the parts during primary school; therefore, the source of the student errors in equalization of the parts, that takes place in the concept of fraction, is the misunderstandings in the primary school.

It is seen that, the students fell into error when they expressed the fraction on the model, they wrote the numerator and denominator in place of each other, and expressed the numerator up to the number of the no scanned division and the denominator up to the number of the scanned division. While there is no similar result in the Literature, the hints of expectations of this result are found in studies conducted by Pesen (2007) and Kocaoglu (2010). In these works, it was emphasized that the part-whole relationship in the concept of fraction should be explained on concrete objects and then by using geometrical shapes such as triangles, rectangles and circles.

It has been determined that the students made error in determining the integer part of the complex fraction, when they were asked to express the fraction corresponding to the point in the given model or on the number line as a complex fraction. It is seen that while students were expressing a fraction between two consecutive numbers, they wrote the proper fraction part without writing the integer part of the fraction. Hence, it can be said that, the students also regard the integer part separately, as they regard the numerator and denominator separately in complex fractions. In addition, it has been seen that students also had difficulty in expressing integers as a fraction. It is determined that, students turn to different ways when determining the numerator and denominator of the integer expression, wrote " 0 " to the numerator or the denominator instead of writing "1" to the denominator while expressing integers as a fraction. It is seen from this that, students do not know that integers state the whole as in the complex fractions. It was also found that students made errors while converting complex fractions to compound fraction. Identified errors are; omitting the integer part in the complex fraction and translocation of numerator and denominator in remaining statement, adding up numerator and denominator and writing it to the denominator or adding up the value in the numerator and denominator and writing it to the numerator. It is understood here that, students had difficulty in converting complex fraction to compound fraction and they turn to different ways to get a compound fraction. It can be argued that students made errors because they did not know why they do these transactions, that they operate by rote and meaningful learning didn't occur.

Another finding in this study is that in the questions that require addition with fractions that have equal denominator, students added up the statements in numerators and wrote it to the numerator; added up the statements in denominators and wrote it to the denominator. In addition, during the subtraction with fractions, students continued to make the same errors and they found the denominator by subtracting the denominators from each other. Also, in similar studies in the Literature, it was concluded that students perceive the numerator and denominator of a fraction as two separate numbers 
(Biber, Tuna \& Aktas, 2013; Haser \& Ubuz, 2002; Meert, Grégoire \& Noël, 2010; Ni \& Zhou, 2005; Pesen, 2008; Soylu \& Soylu, 2005; Stafylidou \& Vosniadou, 2004).

It was observed that, when students were asked to solve problems that require multiplication with fractions, they understood that they need to multiply but they prefer using addition, the alternative, which takes longer to get the result. In addition, it has been determined that the students had transactional difficulty in multiplication of an integer with a fractional expression and because of having troubles in determining the denominator of the integer, they prefer adding up the same fractional statement, that requires multiplication, by writing it alongside the insomuch as necessary.

The student errors that are determined from the questions that ask to get part by giving whole are; dividing the whole with the statement in the numerator and multiplying the obtained result with the expression in the denominator, adding up the given whole with the asked fractional statement instead of multiplication and, multiplying the statements in numerator and denominator that take place in the fraction and subtracting it from the whole. It was seen that the students do not know that the statement in the denominator is the number of equal parts in the whole and the statement in the numerator is the number of asked parts. When the Literature was examined, as a result of the study that was conducted by Karaagac and Kose (2015) with 7th grade students, it is determined that the idea that the amount, that is represented with fractions, changes according to the based whole is not full comprehended by the students, therefore, the concept of part-whole did not fully developed. Again Kocaoglu and Yenilmez (2010) concluded that 5th grade students do not have a part-whole relationship. These two results support the finding that students have difficulty in part-whole relationship.

In this research, it has been determined that students in general cannot make sense of the expressions in the problems and have difficulty in understanding the mathematical discourse. However, it is found that as for some students, they apply random operations with the given numerical statements in the question, for the sake of finding merely a result. Similar to this finding, also in the study conducted by Kocaoglu and Yenilmez (2010) with 5th grade students, it is found that students have difficulty in understanding the problems. One of the causes that lead students to make errors in problem solving is that even though they understand the problem, they incorrectly operate it because of the previous errors that they have while operating with fractions. According to Baki (2008), misunderstandings not only prevent students to learn the topic but also they negatively affect the subsequent learning of students. As it is seen, this detection supports the obtained finding. For this reason, teachers need to be aware of the mistakes that students can make, take these mistakes into consideration in their lessons and plan their lessons in such a way that the students will be prevented to make the same errors. It is believed that teachers need to be informed about the errors, that students have, by both in-service training and seminars. Similarly, it is believed that these errors are needed to be presented to pre-service teachers in field education lessons.

\section{References}

Aksu, M. (1997). Students performance dealing with fractions. The Journal of Educational Research, 90(6), 375-380. https://doi.org/10.1080/00220671.1997.10544595

Alacaci, C. (2010). Misconceptions of students related to fractions. E. Bingölbali and M.F. Özmantar (Ed.), Mathematical Challenges and Solution Suggestions. Ankara: Pegem A Publishing.

Albayrak, M. (2000). Mathematics and Teaching Mathematics in Primary School. Ankara: Aşı1k Printing Press.

Arcavi, A. (2003). A role of visual representations in the learning of mathematics. Educational Studies inMathematics, 52(3), 215-241. https://doi.org/10.1023/A:1024312321077

Baki, A. (2008). Mathematics Education from the Theory to Practice. Ankara: Harf Eğitim Publishing.

Biber, A. C., Tuna, A., \& Aktas, O. (2013). Students' misconceptions of fractions and its effect on solving fractions problems. Trakya University Journal of Education, 3(2), 152-162.

Birgin, O., \& Gurbuz, R. (2009). Primary Education II. Level Students' Operational and Conceptual Knowledge Levels on Rational Numbers. Uludag University Faculty of Education Journal, 22(2), 529-550.

Chan, W. H., Leu, Y. C., \& Chen, C. M. (2007). Exploring group-wise conceptual deficiencies of fractions for fifth and sixth graders in Taiwan. The Journal of Experimental Education, 76(1), 26-57. https://doi.org/10.3200/JEXE.76.1.26-58

Demiri, L. (2013). Researching teachers' and pre-service teachers' knowledge of students' misconceptions about fractions. Unpublished Master Dissertation, Marmara Üniversity, İstanbul.

Devika, R. (2016). Handling fractions and errors in fractions. I-Manager's Journal of Mathematics, 5(3), 1-14.

Haser, C., \& Ubuz, B. (2002). Conceptual and procedural performance in fractions. Education and Science, 27(126), 53-61.

Isik, C., \& Kar, T. (2012). Analyzing problems posed by 7th grade students for addition operation with fractions. Elementary Education Online, 11(4), 1021-1035.

Jigyel, K., \& Afamasaga-Fuata, K. (2007). Student's conceptions of models of fractions and equivalence. Australian 
Mathematics Teacher, 63(4), 17-25.

Karaagac, M. K., \& Kose, L. (2015). Examination of pre-Service and in-service teachers' knowledge of students' misconceptions on the topic of fractions. Sakarya Üniversity Journal of Education Faculty, 30, 72-92.

Kocaoglu, Y. (2010). 5 th grade students' mistakes and misconceptions in solving problems about fractions. Dicle Üniversity Journal of Ziya Gökalp Education Faculty, 14, 71-85.

Mcmillan, H. J., \& Schumacher, S. (2010). Research in education. Boston, USA: Pearson Education.

Meert, G., Grégoire, J., \& Noël, M. P. (2010). Comparing the magnitude of two fractions with commoncomponents: Which representations are used by 10- and 12-year-olds? Journal of Experimental Child Psychology, 107, 244-259. https://doi.org/10.1016/j.jecp.2010.04.008

Moss, J., \& Case, R. (1999). Developing children's understanding of the rational numbers: A new model and experimental curriculum. University of Toronto, Canada. https://doi.org/10.2307/749607

Ni, Y., \& Zhou, Y. D. (2005). Teaching and learning fraction and rational numbers: The origins and implications of whole number bias. Educational Psychologist, 40,27-52. https://doi.org/10.1207/s15326985ep4001_3

Okur, M., \& Cakmak-Gurel, Z. (2016). 6 th and 7th grade secondary school students' misconceptions about fractions. Erzincan University Journal of Education Faculty, 18(2), 922-952.

Olkun, S., \& Toluk, Z. (2003). Activity-based mathematics teaching in primary education. Ankara: Anı Publishing.

Olkun, S., \& Toluk-Ucar, Z. (2012). Activity-based mathematics teaching in primary education. Ankara: Anı Publishing.

Pesen, C. (2007). Students' misconceptions about fractions. Education and Science, 32(143), 79-88.

Pesen, C. (2008). Students' learning difficulties and misconceptions in pointing the fractions on the number line. Inönü University Journal of Education Faculty, 9(15), 157-168.

Redmond, A. (2009). Prospective elementary teachers' division of fractions understanding: A mixed methods study. Unpublished Doctoral Dissertation, Oklahoma State University.

Siap, I., \& Duru, A. (2004). The Ability to Use Geometrical Models in Fractions. Gazi University Kastamonu Education Journal, 12(1), 89-96.

Smith.J. P. (2002).The development of students' knowledge of fractions and ratios. In Litwiller, B. and Bright, G. (Eds).MakingSense of Fractions, Ratios, and Proportions: Yearbook. NCTM: Reston, VA.

Soylu, Y. (2008). Students' errors and misunderstanding at fraction and primary school teachers candidates' prediction skills of error and misunderstanding. Contemporary Education Journal, 33(356), 31-39.

Soylu, Y., \& Soylu, C. (2005). Learning difficulties Of $5 \mathrm{fh}$ class in primary education at fraction: ordering, adding, subtraction, multiplication in fraction and problems related to fraction. Journal of Erzincan Education Faculty, 7(2), 101-117.

Stafylidou, S., \& Vosniadou, S. (2004).The development of students' understanding of the numerical value of fractions. Learning and Instruction, 14, 503-518. https://doi.org/10.1016/j.learninstruc.2004.06.015

Streefland, L. (1991). Fractions in realistic mathematics education: A paradigm of developmental research. Dordrecht, Netherlands: Kluwer. https://doi.org/10.1007/978-94-011-3168-1

Taskin, D., \& Yildiz, C. (2011). Kesirlerde toplama ve çıarma işlemlerinin öğretiminde common knowledge construction modele uygun materyal geliştirme. 2. International Conference on New Trends in Education and Their Implications kongresinde sunulmuş sözlü bildiri. Antalya-Türkiye.

Unlu, M., \& Ertekin, E. (2012). Why do pre-service teachers pose multiplication problems instead of division problems in fractions? Procedia-Social and Behavioral Sciences, 46, 490-494. https://doi.org/10.1016/j.sbspro.2012.05.148

Yenilmez, K., \& Yasa, E. (2008). Primary school students' misconceptions about geometry. Journal of Uludag University Education Faculty, 21(2), 461-483.

Yildirim, A., \& Simsek, H. (2006). Qualitative research methods in the social sciences. Seckin Publishing House, Ankara.

Yilmaz, Z., \& Yenilmez, K. (2008). 7 th and 8th grades students' misconceptions about decimal numbers (The Case of Usak). Afyon Kocatepe University Journal of Science, 8(1), 291-312.

\section{Copyrights}

Copyright for this article is retained by the author(s), with first publication rights granted to the journal.

This is an open-access article distributed under the terms and conditions of the Creative Commons Attribution license which permits unrestricted use, distribution, and reproduction in any medium, provided the original work is properly cited. 